\title{
Expectations and Outcomes of Prolonged Mechanical Ventilation
}

\author{
Christopher E. Cox, MD MPH ${ }^{1}$, Tereza Martinu, MD ${ }^{1}$, Shailaja J. Sathy, MD ${ }^{1}$, Alison S. Clay, \\ MD $^{2}$, Jessica Chia, MD ${ }^{1}$, Alice L. Gray, MD ${ }^{1}$, Maren K. Olsen, PhD ${ }^{3,4}$, Joseph A. Govert, \\ MD ${ }^{1}$, Shannon S. Carson, MD ${ }^{5}$, and James A. Tulsky, MD 6 \\ ${ }^{1}$ Department of Medicine, Division of Pulmonary and Critical Care Medicine, Duke University, \\ Durham, NC; christopher.cox@duke.edu, chia0002@mc.duke.edu, gover001@mc.duke.edu, \\ alice.gray@duke.edu, tereza.martinu@duke.edu, shailaja.sathy@duke.edu \\ 2 Departments of Surgery and Medicine, Duke University, Durham, NC; alison.clay@duke.edu \\ ${ }^{3}$ Center for Health Services Research in Primary Care, VA Medical Center, Durham, NC; \\ olsen008@mc.duke.edu \\ ${ }^{4}$ Department of Biostatistics and Bioinformatics, Duke University, Durham, NC \\ ${ }^{5}$ Department of Medicine, Division of Pulmonary and Critical Care Medicine, University of North \\ Carolina, Chapel Hill, NC; scarson@med.unc.edu \\ ${ }^{6}$ Department of Medicine, Center for Palliative Care, Duke University, Durham, NC; \\ jtulsky@duke.edu
}

\begin{abstract}
Objective: Prolonged mechanical ventilation (PMV) provision is increasing markedly despite poor patient outcomes. Misunderstanding prognosis in the PMV decision making process could provide an explanation to this phenomenon. Therefore, we aimed to compare PMV decision makers' expectations for long-term patient outcomes with prospectively observed outcomes.

Design, Setting, and Patients: 126 patients undergoing PMV, their surrogates, and their intensive care unit physicians were enrolled consecutively (total $n=378$ ) at an academic medical center between April 2006 and April 2007 and followed prospectively for one year.
\end{abstract}

Measurements: Participants were interviewed at the time of tracheostomy placement about their expectations for one-year patient survival, functional status, and quality of life. These expectations were then compared to observed one-year outcomes measured with validated questionnaires.

Results: One-year follow up was $100 \%$, with the exception of patient death or cognitive inability to complete interviews. At one year, only $11(9 \%)$ patients were alive and independent of major functional status limitations. Most surrogates reported high baseline expectations for one-year patient survival (117 [93\%]), functional status (90 [71\%]), and quality of life (105 [83\%]). In contrast, fewer physicians described high expectations for survival (54 [43\%]), functional status (7 [6\%]), and quality of life (5 [4\%]). Surrogate-physician pair concordance in expectations was poor (all $\kappa<0.08$ ), as was their accuracy in outcome prediction (range 23-44\%). Just 33 (26\%) surrogates reported that physicians discussed what to expect for patients' likely future survival, general health, and caregiving needs.

Conclusions: One-year patient outcomes for PMV patients were significantly worse than expected by patients' surrogates and physicians. Lack of prognostication about outcomes, discordance between

Corresponding author: Christopher Cox Duke University Medical Center Division of Pulmonary \& Critical Care Medicine Box 102043 Durham, NC 27710 christopher.cox@ duke.edu Telephone: (919) 681-7232 and fax: (919) 681-8359. 
surrogates and physicians about potential outcomes, and surrogates' unreasonably optimistic expectations appear to be potentially modifiable deficiencies in surrogate-physician interactions.

\section{Keywords}

respiration; artificial; tracheostomy; critical illness; intensive care units; prospective study

\section{INTRODUCTION}

Among the millions of patients admitted to intensive care units (ICUs) annually, approximately one in three will receive mechanical ventilation. (1) Of these, 5-10\% will transition from acute to chronic critical illness and receive prolonged mechanical ventilation (PMV), defined as ventilation for four or more days with tracheostomy placement or for 21 or more days without tracheotomy. (2-4) The majority of PMV patients die within six months while also accruing total annual costs exceeding $\$ 20$ billion. (3,5-8) Survivors often have poor quality of life, pervasive functional and cognitive disability, and intense caregiving needs. $(7,9,10)$ Despite these poor outcomes, the incidence of PMV has been increasing out of proportion to that of mechanical ventilation itself and is forecast to double during the coming decade. $(8,11)$

One explanation for the growth of PMV is that the decision to pursue this level of care may be based on inadequate surrogate-physician interactions. (12) Surrogates often lack knowledge of patients' wishes for life support and have poor comprehension of their medical problems. $(13,14)$ Additionally, others have reported potential contributing deficiencies in ICU-based surrogate-physician communication. $(12,13,15,16)$ However, the physician-surrogate interaction has been infrequently described in the unique setting of PMV consideration, in which a patient has survived an acute illness but yet failed to improve sufficiently to be independent of life support.

In this prospective study, we hypothesized that surrogate-physician concordance in expected long-term patient outcomes would be poor but that physicians' predictions would be substantially better than those of surrogates. We also aimed to characterize important elements of the surrogate-physician interaction surrounding PMV provision.

\section{METHODS}

\section{Study design and study participants}

This prospective study was conducted at Duke University Medical Center between April 2006 and April 2008. Study staff consecutively identified patients by screening all adult ICUs daily between April 2006 and April 2007. Patients were eligible if they were $\geq 18$, had an identifiable surrogate, and had either (a) received mechanical ventilation for $\geq 21$ days with $<48$ hours of unassisted breathing or (b) had received $\geq 4$ days of mechanical ventilation and undergone tracheostomy placement within the previous 48 hours. (2) Exclusions were tracheostomy performed either for an emergency or for an ear, nose, and throat-related diagnosis. "Surrogate" was defined as the person most involved in the decision to place a tracheostomy and the most likely to provide post-discharge caregiving. The Duke University Institutional Review Board approved the protocol.

\section{Hospital outcomes}

Study staff abstracted medical charts to determine patient sociodemographics, length of stay, duration of ventilation, admitting diagnoses, APACHE II-derived acute physiology score (APS), respiratory and laboratory values, and discharge disposition. (17) 


\section{Interviews and follow up}

The timeline of data collection is shown in Figure 1. Baseline (in-hospital) interviews were conducted in person with surrogates, the primary ICU physician involved in the decision to proceed with tracheostomy, and patients (if possible) within 48 hours of tracheostomy placement. Follow-up interviews were performed either by telephone or in person with surrogates and patients at both 3 and 12 months after enrollment, though we report only 12month surrogate responses here. A total of $100 \%$ of interviews were completed for physicians at baseline, as well as surrogates at baseline and 12 months.

During baseline interviews, surrogates completed a questionnaire developed and piloted in a similar population by our group that assessed specific communication, content, and decisionmaking qualities including: whether physicians addressed major risks and implications of PMV provision, who was the primary information source regarding PMV provision, how well surrogates thought physicians explained what to expect for patient outcomes, degree of surrogate-physician conflict regarding PMV decision, overall satisfaction with communication, and overall perceived quality of communication. Surrogates and physicians also answered questions regarding expectations for one year patient survival, functional status, and quality of life. Possible responses to these items were "strongly disagree," "disagree," "agree," and "strongly agree."

Vital status at each follow up was determined by chart review or surrogate interview. Patient functional status was measured in follow up by surrogate report using a six-item instrument addressing limitations in basic daily activities of living (ADL) (bathing, dressing, feeding, transferring from bed to chair, bladder and bowel control, and use of the toilet). (18) To assess patient quality of life, surrogates completed the EuroQOL-5D (EQ-5D), a five-domain, preference-based measure used validated among critical illness survivors and their surrogates. $(19,20)$ An EQ-5D index score calculated from domain scores can range from 0 (death) to 1 (excellent quality of life). We report surrogate EQ-5D reports because only 49 (39\%) patients were able to complete 12-month interviews. However, Pearson's correlations for surrogate and patient EQ-5D scores were high $(r=0.94, p<0.0001)$ while the within-pair mean difference was only $0.09(0.11)$, similar to past studies. (21)

\section{Statistical analyses}

The primary aims were to determine both the concordance of surrogate and physician expectations for one-year patient outcomes (survival, functional status, and quality of life) as well as the accuracy of these expectations. We defined "high expectations" as a response of either "strongly agree" or "agree" to questions regarding whether or not patients were expected (a) to survive one year, (b) to be independent of any major functional limitations, or (c) to have a good quality of life one-year after tracheostomy placement. "Low expectations" reflected responses of "disagree" or "strongly disagree." We defined "good functional status" as the absence of any dependency in ADLs. (18) "Good quality of life" was defined as an EQ-5D index score $>0.44$, a cutoff two standard deviations below the population average for persons aged 55-65. (22)

We performed descriptive analyses using means and medians for continuous variables and frequencies for categorical variables. McNemar's tests and weighted $\kappa$ coefficients were used to describe differences in surrogate-physician pairs' expectations for patients' one-year survival, functional status, and quality of life. $\kappa$ coefficients $<0.20$ represent poor agreement. (23) State software (version 10, College Station, TX) was used for statistical analyses. 


\section{RESULTS}

\section{Characteristics of participants}

Patients were generally middle-aged, married, insured, and functionally independent before hospitalization (see Table 1). They received care in neurological (43 [34\%]), general surgical/ trauma (33 [26\%]), cardiothoracic (23 [18\%]), medical (19 [15\%]) cardiac (8 [5\%]), and ICUs. Surrogates were predominantly female (70\%); half were patients' spouses. We interviewed 54 physicians, $47(87 \%)$ attendings and 7 (13\%) fellows, who cared for two study patients each an average (range 1-10).

\section{Hospital course and observed one-year outcomes}

A total of $70(56 \%)$ patients survived one year after tracheostomy placement, although only $11(9 \%)$ of these survivors had good functional status and $37(33 \%)$ had a good quality of life as assessed by surrogates (Table 2). Forty-three (61\%) of the 70 one-year survivors still required daily informal caregiver assistance. Of these caregivers, 21 (49\%) reported "a lot" or "severe" stress associated with caregiving and $36(84 \%)$ had either quit their job or had significantly altered their work schedule to accommodate their caregiving.

\section{Surrogate-physician interactions}

Only 33 (26\%) surrogates reported that physicians discussed their loved one's prognosis for survival, functional limitations, quality of life, or expected caregiving needs. Also, just 26 (21\%) surrogates reported that physicians had discussed potential consequences of tracheostomy placement including procedural risks, impact on discharge disposition, need for long term ventilator support, and feeding route. Forty-four (35\%) surrogates felt that attending physicians were not the primary source of information about tracheostomy and prolonged mechanical ventilation. In other cases, nurses (19\%), respiratory therapists $(8 \%)$, residents $(8 \%)$, and social workers $(5 \%)$ were the primary informants. A total of $39(31 \%)$ respondents believed that physicians, not themselves, made the decision to provide PMV. Surrogates opted for tracheostomy placement to expedite weaning or improve comfort (45\%), because they felt that the physician wanted them to do it (28\%), to keep the patient alive (23\%), because they were unaware of an alternative (5\%), or to cure the patient (3\%). Serious conflicts with physicians over the tracheostomy decision were reported by 13 (12\%) surrogates. Overall, 91 (72\%) of surrogates felt satisfied with physician communication and $84(67 \%)$ described the quality of surrogate-physician communication as either "extremely good" or "good."

\section{Concordance and accuracy of surrogate and physician expectations}

Expectations-Surrogates had higher expectations than physicians for patient survival, functional status, and quality of life (all $p<0.0001$ by McNemar's tests). Most surrogates expected patients to survive (117 [93\%]) as well as to have no major functional limitations (90 [71\%]) and a good quality of life (105 [83\%]) at one year. In contrast, $55(44 \%)$ physicians had high expectations for patient survival, while only $7(6 \%)$ expected patients to be free of major limitations in functional status and $5(4 \%)$ believed they would have a good quality of life.

Concordance and accuracy of surrogates and physicians' expectations-Both surrogate-physician concordance in expectations (all $\kappa<0.08$ ) and accuracy of outcome prediction was low (see Tables 3, 4, and 5). Although 79 (63\%) surrogates and 91 (72\%) physicians accurately predicted patients' one-year survival, only $56(44 \%)$ pairs were both concordant and accurate (Table 3). Among the surrogates of the 56 patients who died within one year, most expected these same patients to have no major functional limitations (40 [71\%]) and a good quality of life (46 [82\%]). 
The expectations of $52(41 \%)$ surrogates and $93(74 \%)$ physicians were accurately aligned with patients' actual one year limitations in functional ability (Table 4). A total of $39(31 \%)$ of surrogate-physician pairs agreed on expected functional status, while just 29 (23\%) surrogatephysician pairs' expectations matched actual clinical outcomes.

Similarly, 37 (53\%) patients who survived one year were perceived to have poor quality of life at one year (Table 5). A total of 78 (62\%) surrogates and 45 (36\%) physicians accurately predicted patients' one year quality of life. As pairs, $69(55 \%)$ surrogate-physician dyads agreed about expected quality of life, while just 33 (26\%) dyads' expectations were both concordant and accurate compared to observed quality of life.

\section{DISCUSSION}

Decision making in the setting of chronic critical illness is difficult for all involved. One year after the decision to pursue prolonged mechanical ventilation, only $11(9 \%)$ were alive and functionally independent. These outcomes stand in sharp contrast to surrogate-physician pairs' unreasonably high expectations, their low dyadic concordance, and their nearly equal inaccuracy in predicting these observed outcomes.

Surrogates in our study had an especially poor understanding of likely outcomes. However, surrogates' unreasonably high expectations are not surprising given that physicians appeared to infrequently provide them with the basic information necessary for decision making about prolonged life support. In fact, only one quarter of surrogates reported that physicians discussed prognosis while another third obtained the majority of their information from non-physicians. This observation may reflect physicians' general discomfort both with discussing prognosis and in withholding or withdrawing life support in the face of prognostic uncertainty. $(24,25)$ It could also represent surrogates' overwhelming stress or poor comprehension of a loved one's medical condition. $(13,26)$ Physicians' predictions for survival were slightly more accurate, though they were poor at predicting future quality of life. The best known ICU-based predictive models for survival have poor accuracy for those who have received prolonged life support, however. (27) Further, physicians may simply be unaware of the poor outcomes of prolonged mechanical ventilation recipients. $(6,12)$

Although previous studies have demonstrated that severely ill patients and their surrogates are more optimistic than physicians, the dramatic difference in expectations we observed between these groups suggests that the overall effective transfer of information and comprehension of the patient's condition was problematic as well. (28) Nearly a third of surrogates reported that physicians, not themselves, made the decision to place a tracheostomy - a finding that conflicts with most surrogates' preferred role as direct participants in decision making. (29) It also appears that physicians commonly failed to optimize shared decision-making by omitting discussion of alternatives, potential complications, and likely outcomes. However, physicians' avoidance of discussing prognosis conflicts with surrogates' wishes for disclosure of these estimates, even when the outcome is indefinite. (30) Other factors also could have represented barriers to surrogate-physician alignment of expectations including surrogates' numeracy, education level, language and cultural differences; the high prevalence of surrogate psychological and financial distress suffered during the ICU care of their loved one; and the multiple provider ICU environment. (26)

Overall, these summed deficiencies in the surrogate-physician interaction likely heightened the general sense of uncertainty in the decision making process surrounding the provision of prolonged mechanical ventilation. With substantial uncertainty in prognosis and patient preferences for life support, more frequent provision of prolonged mechanical ventilation would be expected. $(12,28,31,32)$ However, this default strategy was associated with 
unanticipated high mortality, profound and chronic disability, as well as significant financial stress and caregiving demands for families - the same poor outcomes that most adults with serious illness report that they would choose to avoid were they to understand the risk. (33)

What can be done to help decision makers set reasonable goals for patient care as well as to plan for the unique needs of patients who subsequently transition from acute to chronic critical illness? Physicians should openly discuss with surrogates both short- and long-term patient prognosis as well as the caregiving burden associated with course of prolonged mechanical ventilation. They should also attempt to understand not only surrogates' expectations and comprehension of prognosis, but why surrogates' perceptions may be misaligned with their own. (13) Family members value information about diagnosis, prognosis, and treatment alternatives even when outcomes are unclear. $(12,30,34)$ Communication interventions in the setting of critical care such as informational leaflets and a protocol-based family conference can improve comprehension and reduce psychological distress. $(35,36)$ Clinicians also can be trained effectively in communication skills. (37) Skilled communication may ensure a patient's wishes are followed appropriately, can result in reduction in time spent in the ICU prior to death, and has been associated with increased family satisfaction. (38-42) A recently published mortality prediction model for prolonged mechanical ventilation may inform the discussion between surrogates and clinicians and improve prognostic accuracy. (43) Decision aids could assist surrogates to navigate the complexities of intensive care. (44) Enhancing communication between physicians and decision makers, particularly when considering treatments for those receiving mechanical ventilation, represents an unmet need as recently emphasized by both the National Institutes of Health and the Joint Commission on the Accreditation of Hospitals. $(45,46)$

Our study has limitations worth noting. Although our cohort was enrolled consecutively from a diverse group of ICUs, the findings of a single center study may not reflect the experience of other medical centers. We used proxy measures of health status and quality of life in our analyses that could have underestimated patients' perceptions of these outcomes. However, surrogates' and patients' measures were highly correlated and the absolute difference between groups' scores was low. Further, a large number of patients were unable to complete interviews because of disability during follow up, though this observation itself is testament to the profound disability patients experienced. Finally, because we did not audiotape family meetings, we can rely only on surrogates' potentially inaccurate descriptions of these interactions.

\section{Conclusions}

The substituted judgment of a surrogate is an integral but complicated component of the decision to provide prolonged mechanical ventilation. (47) This decision has important implications for patients, their families, healthcare providers, and the healthcare system. (6) We found a dramatic degree of surrogate-physician discord and inaccuracy in expectations for outcomes that appeared to be related to the content of ICU-based interactions. At the time surrogates made the decision to proceed with the provision of prolonged mechanical ventilation they expected neither the profound disability patients later experienced nor its associated caregiver burden. Improving the content and quality of the surrogate-physician interaction should be a target for future study in this challenging, expanding population of chronically critically ill patients. $(11,48-50)$

\section{Acknowledgments}

Support: National Institutes of Health grants K23 HL081048 (CEC) and K23 HL067068 (SSC). 


\section{REFERENCES}

1. Esteban A, Anzueto A, Frutos F, et al. Characteristics and outcomes in adult patients receiving mechanical ventilation: a 28-day international study. JAMA 2002;287:345-355. [PubMed: 11790214]

2. MacIntyre NR, Epstein SK, Carson S, et al. Management of patients requiring prolonged mechanical ventilation: report of a NAMDRC consensus conference. Chest 2005;128:3937-3954. [PubMed: 16354866]

3. Carson SS, Bach PB. The epidemiology and costs of chronic critical illness. Crit Care Clin 2002;18:461-476. [PubMed: 12140908]

4. Frutos-Vivar F, Esteban A, Apezteguia C, et al. Outcome of mechanically ventilated patients who require a tracheostomy. Crit Care Med 2005;33:290-298. [PubMed: 15699830]

5. Carson SS, Bach PB, Brzozowski L, Leff A. Outcomes after long-term acute care: An analysis of 133 mechanically ventilated patients. Am J Respir Crit Care Med 1999;159:1568-1573. [PubMed: 10228128]

6. Cox CE, Carson SS, Govert JA, et al. An economic evaluation of prolonged mechanical ventilation. Crit Care Med 2007;35:1918-1927. [PubMed: 17581479]

7. Cox CE, Carson SS, Hoff-Linquist JA, et al. Differences in one-year health outcomes and resource utilization by definition of prolonged mechanical ventilation: a prospective cohort study. Crit Care 2007;11:R9. [PubMed: 17244364]

8. Zilberberg MD, Luippold RS, Sulsky S, Shorr AF. Prolonged acute mechanical ventilation, hospital resource utilization, and mortality in the United States. Crit Care Med 2008;36:724-730. [PubMed: 18209667]

9. Nelson JE, Meier DE, Litke A, et al. The symptom burden of chronic critical illness. Crit Care Med 2004;32:1527-1534. [PubMed: 15241097]

10. Nelson JE, Tandon N, Mercado AF, et al. Brain dysfunction: another burden for the chronically critically ill. Arch Intern Med 2006;166:1993-1999. [PubMed: 17030833]

11. Cox CE, Carson SS, Holmes GM, et al. Increase in tracheostomy for prolonged mechanical ventilation in North Carolina, 1993-2002. Crit Care Med 2004;32:2219-2226. [PubMed: 15640633]

12. Nelson JE, Mercado AF, Camhi SL, et al. Communication about chronic critical illness. Arch Intern Med 2007;167:2509-2515. [PubMed: 18071175]

13. Azoulay E, Chevret S, Leleu G, et al. Half the families of intensive care unit patients experience inadequate communication with physicians. Crit Care Med 2000;28:3044-3049. [PubMed: 10966293]

14. Cohen S, Sprung C, et al. Communication of end-of-life decisions in European intensive care units. Intensive Care Med 2005;31:1215-1221. [PubMed: 16041519]

15. The SUPPORT Investigators. A controlled trial to improve care for seriously ill hospitalized patients: the study to understand prognoses and preferences for outcomes and risks of treatments. JAMA 1995;274:1591-1598. [PubMed: 7474243]

16. Abbott KH, Sago JG, Breen CM, et al. Families looking back: one year after discussion of withdrawal or withholding of life-sustaining support. Crit Care Med 2001;29:197-201. [PubMed: 11176185]

17. Knaus WA, Draper EA, Wagner DP, Zimmerman JE. APACHE II: a severity of disease classification system. Crit Care Med 1985;13:818-829. [PubMed: 3928249]

18. Katz S, Ford AB, Moskowitz RW, et al. The index of ADL: a standardized measure of biological and physiological function. JAMA 1963;185:914-919. [PubMed: 14044222]

19. The EuroQol Group. EuroQol--a new facility for the measurement of health-related quality of life. Health Policy 1990;16:199-208. [PubMed: 10109801]

20. Angus DC, Carlet J. Surviving Intensive Care: a report from the 2002 Brussels Roundtable. Intensive Care Med 2003;29:368-377. [PubMed: 12536269]

21. Tsevat J, Cook EF, Green ML, et al. Health values of the seriously ill. SUPPORT investigators. Ann Intern Med 1995;122:514-520. [PubMed: 7872587]

22. Kind, P.; Hardman, G.; Macran, S. UK population norms for the EQ-5D. Available online at: http://www.york.ac.uk/inst/che/pdf/DP172.pdf. Accessed April 18, 2008 
23. Altman, DG. Practical statistics for medical research. Chapeman and Hall/CRC; London, England: 1991.

24. Christakis NA, Asch DA. Biases in how physicians choose to withdraw life support. Lancet 1993;342:642-646. [PubMed: 8103146]

25. White DB, Engelberg RA, Wenrich MD, et al. Prognostication during physician-family discussions about limiting life support in intensive care units. Crit Care Med 2007;35:442-448. [PubMed: 17205000]

26. Pochard F, Azoulay E, Chevret S, et al. Symptoms of anxiety and depression in family members of intensive care unit patients: ethical hypothesis regarding decision-making capacity. Crit Care Med 2001;29:1893-1897. [PubMed: 11588447]

27. Carson SS, Bach PB. Predicting mortality in patients suffering from prolonged critical illness: an assessment of four severity-of-illness measures. Chest 2001;120:928-933. [PubMed: 11555531]

28. Weeks JC, Cook EF, O'Day SJ, et al. Relationship between cancer patients' predictions of prognosis and their treatment preferences. JAMA 1998;279:1709-1714. [PubMed: 9624023]

29. Heyland DK, Cook DJ, Rocker GM, et al. Decision-making in the ICU: perspectives of the substitute decision-maker. Intensive Care Med 2003;29:75-82. [PubMed: 12528026]

30. Evans LR, Boyd EA, Malvar G, et al. Surrogate Decision Makers' Perspectives on Discussing Prognosis in the Face of Uncertainty. Am J Respir Crit Care Med. 2008doi:10.1164/rccm. 200806-9690C

31. Van Pelt DC, Milbrandt EB, Qin L, et al. Informal caregiver burden among survivors of prolonged mechanical ventilation. Am J Respir Crit Care Med 2007;175:167-173. [PubMed: 17068327]

32. Luce JM, White DB. The pressure to withhold or withdraw life-sustaining therapy from critically ill patients in the United States. Am J Respir Crit Care Med 2007;175:1104-1108. [PubMed: 17379853]

33. Fried TR, Bradley EH, Towle VR, Allore H. Understanding the treatment preferences of seriously ill patients. N Engl J Med 2002;346:1061-1066. [PubMed: 11932474]

34. Azoulay E, Sprung CL. Family-physician interactions in the intensive care unit. Crit Care Med 2004;32:2323-2328. [PubMed: 15640649]

35. Azoulay E, Pochard F, Chevret S, et al. Impact of a family information leaflet on effectiveness of information provided to family members of intensive care unit patients: a multicenter, prospective, randomized, controlled trial. Am J Respir Crit Care Med 2002;165:438-442. [PubMed: 11850333]

36. Lautrette A, Darmon M, Megarbane B, et al. A communication strategy and brochure for relatives of patients dying in the ICU. N Engl J Med 2007;356:469-478. [PubMed: 17267907]

37. Back AL, Arnold RM, Baile WF, et al. Efficacy of communication skills training for giving bad news and discussing transitions to palliative care. Arch Intern Med 2007;167:453-460. [PubMed: 17353492]

38. Curtis JR, Engelberg RA, Wenrich MD, et al. Missed opportunities during family conferences about end-of-life care in the intensive care unit. Am J Respir Crit Care Med 2005;171:844-849. [PubMed: 15640361]

39. Lilly CM, De Meo DL, Sonna LA, et al. An intensive communication intervention for the critically ill. Am J Med 2000;109:469-475. [PubMed: 11042236]

40. McDonagh JR, Elliott TB, Engelberg RA, et al. Family satisfaction with family conferences about end-of-life care in the intensive care unit: increased proportion of family speech is associated with increased satisfaction. Crit Care Med 2004;32:1484-1488. [PubMed: 15241092]

41. Stapleton RD, Engelberg RA, Wenrich MD, et al. Clinician statements and family satisfaction with family conferences in the intensive care unit. Crit Care Med 2006;34:1679-1685. [PubMed: 16625131]

42. Schneiderman LJ, Gilmer T, Teetzel HD, et al. Effect of ethics consultations on nonbeneficial lifesustaining treatments in the intensive care setting: a randomized controlled trial. JAMA 2003;290:1166-1172. [PubMed: 12952998]

43. Carson SS, Garrett J, Hanson LC, et al. A prognostic model for one-year mortality in patients requiring prolonged mechanical ventilation. Crit Care Med 2008;36:2061-2069. [PubMed: 18552692]

44. Dales RE, O'Connor A, Hebert P, et al. Intubation and mechanical ventilation for COPD: development of an instrument to elicit patient preferences. Chest 1999;116:792-800. [PubMed: 10492288] 
45. National Institutes of Health State of the Science Conference Statement. Improving end of life care. Available at: consensus.nih.gov/2004/2004EndOfLifeCareSOS024PDF.pdf. Accessed July 2, 2008

46. Joint Committee on the Accreditation of Healthcare Organizations. What did the doctor say? Improving health literacy to protect patient safety. Available at: www.jointcommission.org/NR/rdonlyres/D5248B2E-E7E6-4121-8874-99C7B4888301/0/ improving_health_literacy.pdf. Accessed June 30, 2008

47. Berger JT, DeRenzo EG, Schwartz J. Surrogate decision making: reconciling ethical theory and clinical practice. Ann Intern Med 2008;149:48-53. [PubMed: 18591637]

48. Zilberberg MD, de Wit M, Pirone JR, Shorr AF. Growth in adult prolonged acute mechanical ventilation: implications for healthcare delivery. Crit Care Med 2008;36:1451-1455. [PubMed: 18434911]

49. Pear R. White House Offers Grim Outlook for Medicare. New York Times. March 25;2008

50. Angus DC, Kelley MA, Schmitz RJ, White A, Popovich J Jr. Current and projected workforce requirements for care of the critically ill and patients with pulmonary disease: can we meet the requirements of an aging population? JAMA 2000;284:2762-2770. [PubMed: 11105183] 


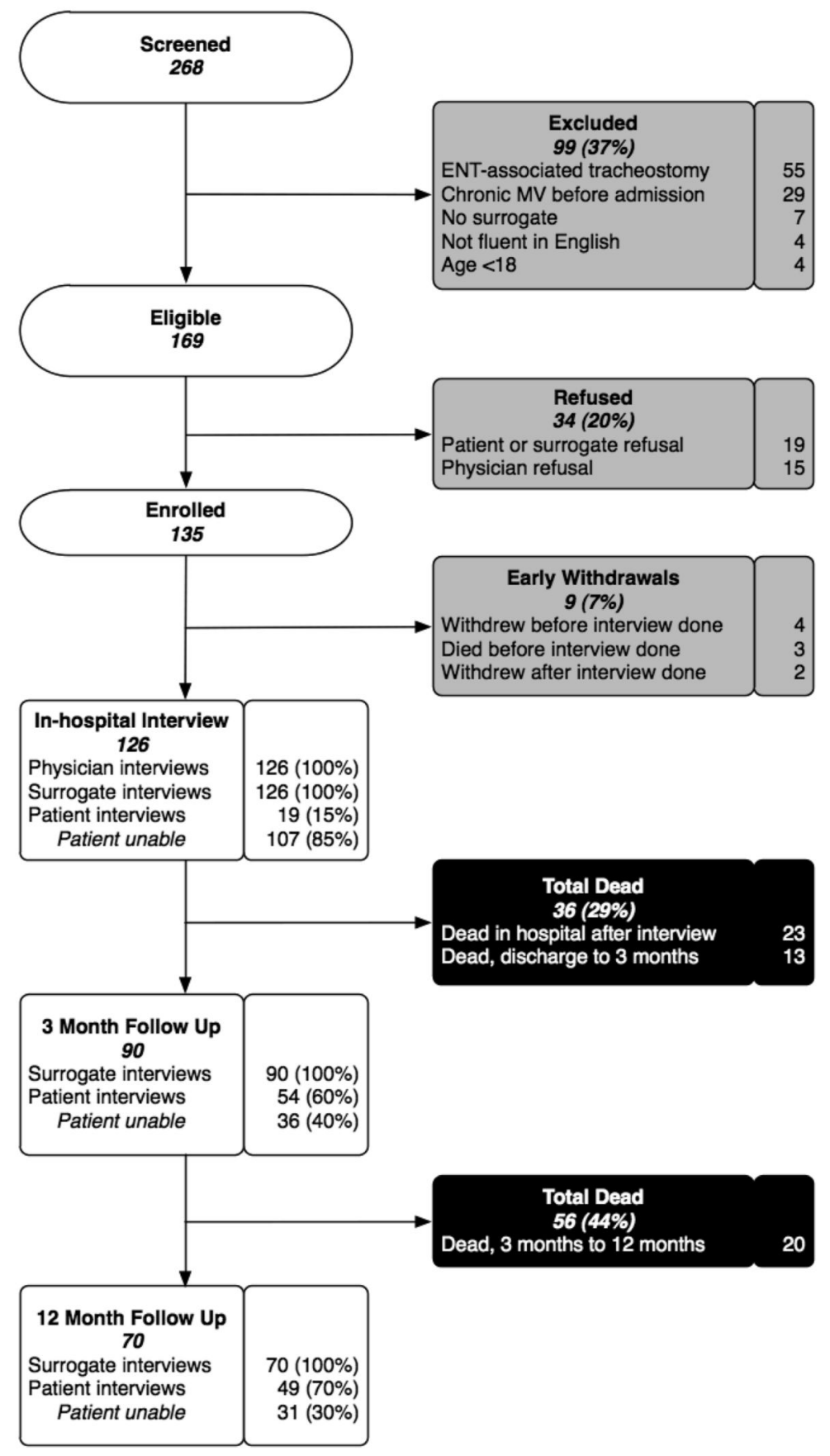

Figure 1. Enrollment and follow up of patients and surrogates

This figure depicts study participant enrollment and outcomes over one year of follow up. 
Table 1

Baseline characteristics of patients and surrogates

\begin{tabular}{|c|c|c|}
\hline & Patients & Surrogates \\
\hline Age & $57(45,67)$ & $55(47,61)$ \\
\hline Female & $50(40 \%)$ & $90(71 \%)$ \\
\hline \multicolumn{3}{|l|}{ Race \& ethnicity } \\
\hline White & $67(53 \%)$ & $72(57 \%)$ \\
\hline African-American & $48(38 \%)$ & $48(38 \%)$ \\
\hline Native American & $7(5 \%)$ & $5(4 \%)$ \\
\hline Asian & $2(2 \%)$ & $0(0 \%)$ \\
\hline Hispanic & $2(2 \%)$ & $1(1 \%)$ \\
\hline \multicolumn{3}{|c|}{ Place of residency before admission } \\
\hline Home & $124(98 \%)$ & $\mathrm{n} / \mathrm{a}$ \\
\hline \multirow{2}{*}{\multicolumn{3}{|c|}{$\begin{array}{l}\text { Nursing facility } \\
\text { Employment status }\end{array}$}} \\
\hline & & \\
\hline Employed & $41(32 \%)$ & $65(51 \%)$ \\
\hline Unemployed or student & $18(14 \%)$ & $15(12 \%)$ \\
\hline Retired & $41(33 \%)$ & $35(28 \%)$ \\
\hline Disabled & $26(21 \%)$ & $11(9 \%)$ \\
\hline \multicolumn{3}{|l|}{ Marital status } \\
\hline Married or living w/ partner & $73(58 \%)$ & $89(71 \%)$ \\
\hline Unmarried & $24(19 \%)$ & $17(13 \%)$ \\
\hline Separated or divorced & $20(16 \%)$ & $11(9 \%)$ \\
\hline Widowed & $9(7 \%)$ & $9(7 \%)$ \\
\hline \multicolumn{3}{|l|}{ Surrogate relationship to patient } \\
\hline Spouse or partner & & $63(50 \%)$ \\
\hline Sibling & & $13(10 \%)$ \\
\hline Other family member & & $49(39 \%)$ \\
\hline Friend & & $1(1 \%)$ \\
\hline \multicolumn{3}{|l|}{ High school or greater education ${ }^{a}$} \\
\hline Less than high school & $15(14 \%)$ & $9(8 \%)$ \\
\hline Completed high school or GED & $63(58 \%)$ & $52(48 \%)$ \\
\hline Completed college & $21(20 \%)$ & $28(26 \%)$ \\
\hline Graduate or professional school & $9(8 \%)$ & $19(18 \%)$ \\
\hline Insured & $80(85 \%)$ & $\mathrm{n} / \mathrm{a}$ \\
\hline Charlson comorbidity score ${ }^{b}$ & $2(0,4)$ & $\mathrm{n} / \mathrm{a}$ \\
\hline Deeply religious ${ }^{c}$ & $16(80 \%)$ & $77(71 \%)$ \\
\hline
\end{tabular}

$n=126$ patients and 126 surrogates. Results as number (\%) or median (interquartile range).

$\mathrm{GED}=$ general education development, $\mathrm{n} / \mathrm{a}=$ not applicable .

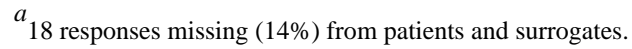

${ }^{b}$ Per surrogate interview and chart review.

${ }^{c} 106(84 \%)$ responses missing from patients and $18(14 \%)$ from surrogates. 


\section{Table 2}

Clinical characteristics and outcomes of patients

$n(\%)$

Primary ICU admission diagnosis ${ }^{a}$

Respiratory failure

Neurological

Trauma

Post-operative

Septic shock

Cardiac

APS, ICU day $1^{b}$

Days of ventilator use ${ }^{c}$

ICU length of stay

Hospital length of stay

Discharge disposition

Home independent

Home with paid care

Long-term acute care facility

Skilled nursing facility

Rehabilitation facility

Other hospital

Still in acute care hospital at one year

Dead

Withdrawal of MV

Cardiac arrest

One year outcomes

Survival

Good functional status $d$

Good quality of life ${ }^{e}$

$30(24 \%)$
$29(23 \%)$
$26(20.5 \%)$
$26(20.5 \%)$
$10(8 \%)$
$5(4 \%)$
$19(15,24)$
$32(19,48)$; range 3-365
$26(21,42)$
$39(28,57)$
$7(6 \%)$
$14(11 \%)$
$37(30 \%)$
$19(15 \%)$
$23(18 \%)$
$2(2 \%)$
$1(1 \%)$
$23(18 \%)$
$20(87 \%)$
$3(13 \%)$
$70(56 \%)$
$11(9 \%)$
$33(26 \%)$

$n=126$. Values displayed as $n(\%)$ or median (interquartile range). APS=acute physiology score, ICU=intensive care unit, MV=mechanical ventilation.

${ }^{a}$ Respiratory includes pneumonia, aspiration, and pulmonary embolus; neurological includes ischemic stroke, subarachnoid hemorrhage, Guillain-Barre, and status epilepticus; post-operative denotes failure to wean or reintubation within 48 hours from index surgery; cardiac includes myocardial infarction and cardiac arrest.

${ }^{b}$ From APACHE II classification.

${ }^{c}$ Includes post-acute care facility-based ventilator days.

$d_{\text {Surrogate-assessed functional status with good functional status defined as no major dependencies measured by Activities of Daily Living instrument }}$ (see Methods).

${ }^{e}$ Surrogate-assessed quality of life with good quality of life defined as EQ-5D score $\geq 0.44$ (see Methods). 


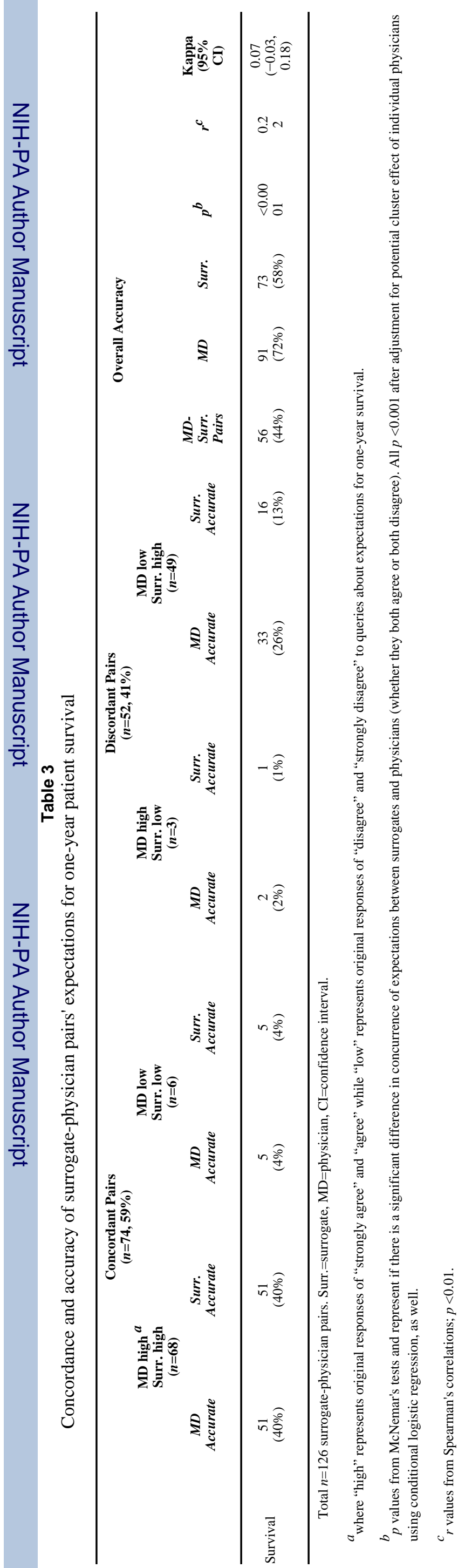




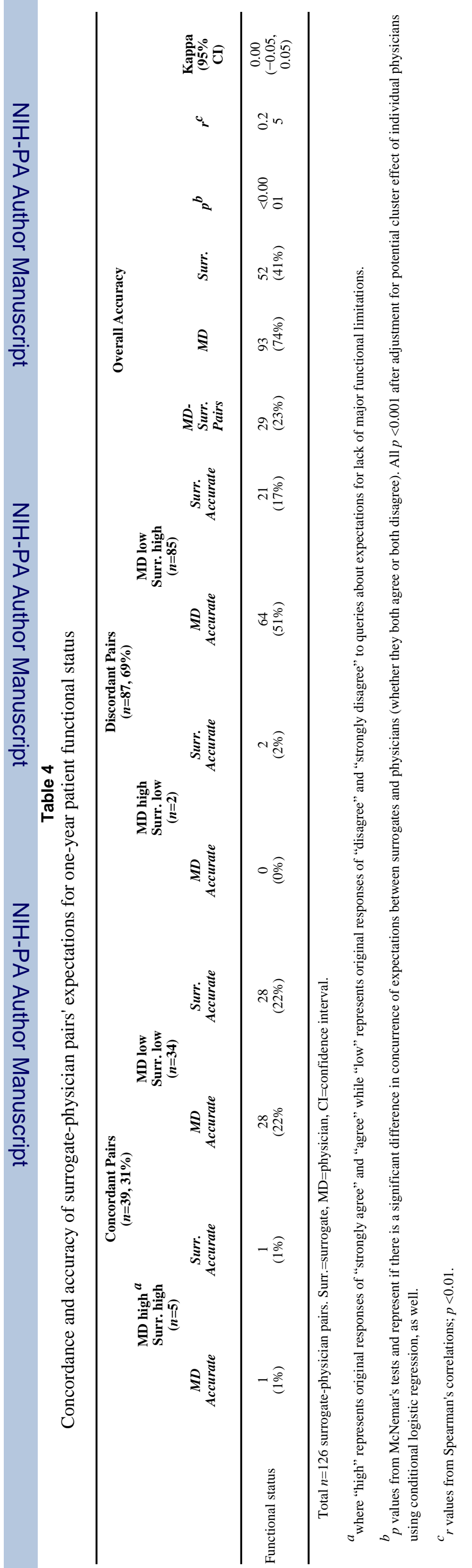




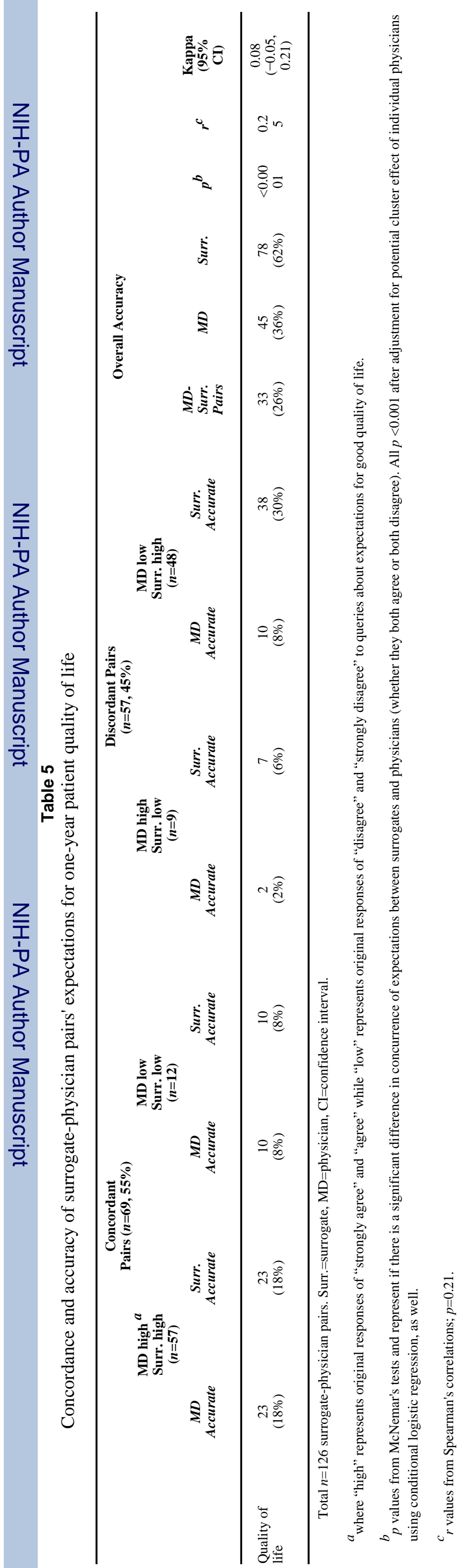

